\title{
HÁ FUTURO PARA AS REVISTAS DAS SOCIEDADES CIENTÍFICAS?
}

Duas recentes publicações chamaram nossa atenção e gostaríamos de discuti-las um pouco com a nossa comunidade: a nota do Prof. Silvio R. A. Salinas no Boletim 010/2010 da Sociedade Brasileira de Física (SBF) sobre o tema "Associação entre a Springer e o Brazilian Journal of Physics"1 e o editorial da revista Science, de 22 de janeiro de 2010, sobre o tema "Improving Access to Research".2

A SBF encontra-se no dilema de licenciar, ou não, o Brazilian Journal of Physics para a editora Springer visando aumentar sua inserção internacional, seguindo modelo adotado por algumas revistas brasileiras e de outros países. O editorial da Science destaca aspectos do relatório do comitê da $U$. S. House Science and Technology sobre disponibilização, ao público, das publicações das pesquisas financiadas com fundos federais, o mais rapidamente possível, em até um ano ou menos após a publicação. O relatório não mostra uma direção a ser seguida, mas faz diversas recomendações, uma delas às agências de financiamento à pesquisa para que desenvolvam políticas de amplo acesso aos resultados das pesquisas realizadas com recursos públicos. Se esta política avançar é possível que as revistas de acesso livre na rede sejam mais procuradas, mesmo aquelas que cobram para liberar este acesso.

Mesmo após várias tentativas de conglomerados internacionais de adquirirem o controle do Journal of the Brazilian Chemical Society, as revistas da SBQ continuam de acesso livre na rede tanto no site da SBQ, como no portal Scielo, por entendermos que esta política é inteiramente compatível com o processo rigoroso de avaliação pelos pares e os autores de artigos cedem os direitos autorais de seus trabalhos para a SBQ. Apoiamos integralmente o Scielo que é um empreendimento nacional, mas com ramificações internacionais. Os custos de espaço no seu servidor e processamento dos artigos aceitos são arcados com recursos públicos. A ampliação e a inserção internacional do Scielo mostram claramente seu sucesso, que vai em sentido contrário ao poder econômico das grandes editoras internacionais, que cobram valores exorbitantes por um artigo.

As nossas revistas conseguiram alcançar índices de impactos consideráveis, devido a sua credibilidade junto à comunidade científica e muita luta do corpo editorial para evitar o complexo de inferioridade que acomete muitos dos nossos colegas. Sempre convocamos a comunidade a publicar seus bons artigos no $J B C S$ e $Q N$, e não aqueles que foram rejeitados por outras revistas, e citarem artigos publicados anteriormente nos dois periódicos. Muitos atenderam, mas ainda temos colegas que preferem publicar artigos em revistas similares e, às vezes, até inferiores com o argumento que as nossas revistas são muito exigentes. No passado, algumas revistas exigiam o número da publicação no Chemical Abstracts quando havia citação de um artigo do $J B C S$ e $Q N$. Hoje não existe mais isso. Então, a não citação de um artigo publicado em uma revista nacional parecer ser uma questão de inferioridade cultural. Parece que alguns autores acham que citar um destes trabalhos vai desvalorizar seu manuscrito.

As políticas das agências finaciadoras devem privilegiar as revistas nacionais de boa qualidade, para não vermos no futuro todos os nosso periódicos nas mãos das grandes editoras internacionais. Os comitê avaliadores destas agências deveriam refletir bastante sobre esse tema e como suas decissões podem afetar o futuro das revistas das sociedades científicas. O mais estranho de tudo isso é ter que pagar a um grupo editorial internacional, com recursos públicos, o acesso a uma revista brasileira cujos artigos foram financiados com recursos públicos do Brasil.

No título deste editorial perguntamos se há futuro para as revistas das sociedades científicas. Em nossa opinião, o futuro está em nossas mãos, como cientistas e membros dos comitês das agências financiadoras. Cada qual deve cumprir adequadamente o seu papel. As Agências de Governo financiando as revistas, as Sociedades Científicas mantendo linhas de editoria que privilegiem a qualidade, os membros de Comitês Científicos valorizando o mérito, independentemente de onde é publicado e, por último, mas não menos importante, a comunidade científica que submete e avalia os artigos, deve ser a garantia da qualidade e da visibilidade das publicações.

Finalizando, destacamos três parágrafos do editorial da SBF: "Aqui no Brasil os químicos resistem, prestigiam as suas revistas"; "Mas os químicos continuam no SCIELO, e se orgulham do apoio às suas revistas, o Journal of the Brazilian Chemical Society, com índices de impacto entre 1 e 1.5, e Química Nova, publicada quase exclusivamente em português, que já atingiu índices bem mais expressivos do que o BJP" e "Qual a mágica dos químicos para apoiar as publicações nacionais?"; que esperamos ter respondido nos parágrafos precedentes.

Susana I. Córdoba de Torresi
Vera L. Pardini
Vitor F. Ferreira
Editores de QN
Jailson B. de Andrade
Editor do JBCS

\section{REFERÊNCIAS}

1. Salinas, S. R. A.; Boletim SBF 010/2010; http://www.sbf1.sbfisica.org. br/boletim1/msg201.htm, acessada em Fevereiro 2010.

2. Courant, P. N.; O’Donnell, J. J.; Okerson, A.; Taylor, C. B.; Science 2010, 327, 393. 